\title{
The role of insulin detemir in overweight type 2 diabetes management
}

This article was published in the following Dove Press journal:

Vascular Health and Risk Management

24 June 2009

Number of times this article has been viewed

\author{
Yared N Demssie \\ Naveed Younis ${ }^{2}$ \\ Handrean Soran ${ }^{3}$ \\ 'Department of Diabetes \\ and Endocrinology, Salford Royal \\ Foundation NHS Trust, Salford, \\ UK; ${ }^{2}$ Department of Medicine, \\ University Hospital South \\ Manchester Foundation NHS Trust, \\ Wythenshawe, Manchester, UK; \\ ${ }^{3}$ University Department of Medicine, \\ Central Manchester and Manchester \\ Children's NHS Foundation Trust, \\ Manchester, UK
}

\begin{abstract}
The recent evidence-based shift towards an algorithm of early initiation and aggressive titration of insulin therapy in the management of type 2 diabetes requires the use of an effective insulin formulation that is both safe and acceptable to patients and physicians alike. The advent of the long-acting insulin analogues, insulin detemir and glargine, in the last decade has revolutionized insulin therapy in type 2 diabetes. Their unique pharmacokinetic and pharmacodynamic properties have offered tangible advantage over the conventional intermediate and long-acting insulin preparations in terms of improving glucose control as well as reducing risk of hypoglycemia and weight gain. This review focuses on the pharmacodynamic properties of the long-acting insulin analogue detemir, the outcome of studies on its relative efficacy and safety as well as its proposed place in the management of type 2 diabetes.
\end{abstract}

Keywords: insulin detemir, type 2 diabetes, overweight

\section{Introduction to management of type 2 diabetes}

The benefits of intensive glucose lowering treatment in reducing the risk of microvascular complications in both type 1 and type 2 diabetes has already been confirmed from the outcome of the landmark Diabetes Control and Complications Trial (DCCT) and United Kingdom Prospective Diabetes Study (UKPDS) trials. ${ }^{1,2}$ A recent 10-year follow-up study of the UKPDS cohort also showed long-term beneficial effects of intensive glucose control in reducing cardiovascular and all cause mortality. ${ }^{3}$ In recognition of these facts, a tighter glycemic target has been recommended by the American Diabetes Association (ADA) and International Diabetes Federation (IDF) aiming for $\mathrm{HbA}_{1 \mathrm{c}}$ of $<7 \%$ and $<6.5 \%$ respectively. ${ }^{4,5}$ However, studies have shown that more than two thirds of patients with type 2 diabetes fail to meet the recommended $\mathrm{HbA}_{1 \mathrm{c}}$ target of $<7 \%$ despite half of this population being on at least two oral antidiabetes agents (OADs). ${ }^{6}$

Although a dietary and exercise program with or without metformin constitutes to be the first line treatment for the majority of newly diagnosed type 2 diabetes patients, most of these patients will eventually require the addition of insulin therapy due to progressive decline in beta cell function. ${ }^{7}$ The joint ADA/ European Association for the Study of Diabetes (EASD) consensus statement on treatment for type 2 diabetes therefore recommends the early initiation of insulin therapy in the form of basal insulin combined with OADs to achieve optimal glucose control. ${ }^{8}$

\section{Limitations of insulin therapy}

In addition to the fear of needles, the risk of hypoglycemia and weight gain remains a major obstacle towards initiation and titration of insulin treatment. Hypoglycemia 
is widely considered as a main factor that limits the scope for aggressive insulin therapy. In the DCCT, the relative risk of severe hypoglycemia for type 1 diabetes patients who received intensive insulin therapy was 3.28 greater compared to those who were on conventional therapy. ${ }^{1}$ Similarly, in the UKPDS trial, patients assigned to intensive insulin treatment had a higher annual incidence of major hypoglycemia $(1.8 \%)^{2}$

Insulin associated weight gain is also of particular concern in type 2 diabetes, a condition in which $80 \%$ to $90 \%$ of the population is already overweight. ${ }^{9}$ In UKPDS, patients who received intensive insulin therapy gained more weight $(4 \mathrm{~kg}$ ) compared to those in the conventional treatment group. Moreover, the rate of weight gain was noted to be at its fastest during the initial phase of insulin treatment, which is a crucial time of adjustment for the insulin-naive patient thereby potentially influencing long-term compliance. The predominantly central or visceral distribution of insulin associated weight gain is correlated with increased insulin resistance and cardiovascular risk, further undermining the benefits of improved glucose control. ${ }^{10,11}$ Weight gain is also adversely affects blood pressure and lipid profile. ${ }^{12-15}$

The proposed mechanisms for insulin associated weight gain are multiple including defensive snacking to avert hypoglycemia, calorie retention from decreased glycosuria and the abnormal peripheral to hepatic insulin balance that exists with exogenous insulin use leading to increased hepatic glucose output and peripheral lipogenesis. ${ }^{16-18}$ The main predictors of insulin related weight gain are high initial glycemic level, degree of improvement in glucose control, number of insulin injections and mean daily insulin dose. ${ }^{13,19}$ Thus, the patients who are at risk for insulin associated weight gain are the very ones who need insulin the most (those with poor control) and those who have responded well to treatment.

\section{Basal insulin therapy in type 2 diabetes}

An ideal insulin therapy regime would mimic the normal physiology of endogenous insulin production characterized by a smooth peak-less basal delivery of insulin in the fasting and interprandial state to suppress hepatic gluconeogenesis along with prandial boosts of insulin to prevent meal related glucose excursions. The so-called basal-bolus regimen of insulin therapy, which is widely used in both type 1 and type 2 diabetes, employs this physiologic concept by combining a long-acting basal insulin with short acting prandial insulin formulations. Basal insulin can also be used in conjunction with insulin sensitizing OADs in type 2 diabetes.
This latter approach has been shown to be effective in limiting insulin requirements, minimizing weight gain and offer some cardiovascular protective effect. ${ }^{20,21}$

Until the recent advent of long-acting insulin analogues, basal insulin therapy was only available in the form of zinc or protamine retarded preparations of porcine or human insulin. Upon subcutaneous injection, the suspended precipitates of these insulin formulations slowly dissolve to prolong absorption into the peripheral circulation and provide a low but continuous supply of basal insulin in the fasting state. However, conventional intermediate and long-acting human basal insulin preparations such as neutral protamine hagedorn (NPH) fall short of the ideal physiologic smooth delivery of basal insulin because of their poor pharmacokinetics profile characterized by pronounced peaks (4 to 20 hours after injection) and marked intrasubject variability which predisposes patients to hypoglycemia (Table 1).

Hypoglycemia is therefore not a direct consequence of intensive glucose control strategy but a reflection of the inherent pharmacodynamic shortcomings of conventional insulin preparations to closely match insulin levels to physiological needs. To this end, the introduction of the basal insulin analogues detemir and glargine with no significant peak activity, longer duration of action, less variability and hence lower risk of hypoglycemia has been a welcome development.

\section{Insulin detemir, pharmacokinetics and pharmacodynamics}

Insulin detemir [B29Lys(myristoyl), des (B30)] is a long-acting insulin analogue produced by recombinant DNA technology that involves the deletion of the amino acid threonine at the B-30 locus and the acylation of a 14-carbon fatty acid called myristic acid to lysine at B-29 locus of the insulin molecule (Figure 1). This structural modification of the human insulin molecule allows self association of hexamers within the injection depot as well as promoting reversible binding to albumin in the plasma and interstitial fluid which mediates its slow absorption from the subcutaneous site leading to protracted duration of action. ${ }^{22,23}$

Its soluble nature removes the need for resuspension and the potential for precipitation upon injection which accounts for its reproducible and predictable action. Detemir's reversible binding to albumin also buffers short-term changes in absorption rates from the subcutaneous tissue, additional mechanism that explains its tendency for reduced intrapatient variability compared to NPH and insulin glargine. ${ }^{24,25}$ Insulin glargine is another long-acting insulin analogue produced by adding two arginine residues to the $\mathrm{C}$-terminus of the $\mathrm{B}$-chain 
Table I Pharmacokinetics of intermediate and long-acting insulin preparations

\begin{tabular}{|c|c|c|c|}
\hline Type of insulin & Onset & Peak effect & Duration (hours) \\
\hline \multicolumn{4}{|l|}{ Intermediate-acting } \\
\hline Semilente & $0.5-1$ & $4-6$ & $8-12$ \\
\hline Lente & $2-4$ & $6-10$ & $12-24$ \\
\hline Isophane/NPH & $2-4$ & $6-10$ & $12-24$ \\
\hline \multicolumn{4}{|l|}{ Long-acting } \\
\hline Ultralente & $3-4$ & $8-20$ & $20-36$ \\
\hline Protamine zinc & $3-4$ & $14-20$ & $24-36$ \\
\hline \multicolumn{4}{|c|}{ Long-acting analogues } \\
\hline Glargine & 2 & $\begin{array}{l}\text { no pronounced } \\
\text { peak }\end{array}$ & 22 \\
\hline Detemir & 2 & $\begin{array}{l}\text { no pronounced } \\
\text { peak }\end{array}$ & $\begin{array}{l}20 \text { for doses } \\
>0.4 \text { units } / \mathrm{kg}\end{array}$ \\
\hline
\end{tabular}

and replacing the asparagine residue at A-21 with a neutral glycine residue, rendering it less soluble at the physiological $\mathrm{pH}$ of subcutaneous tissue and delaying absorption with duration of action of up to 24 hours. ${ }^{26}$

An additional proposed benefit of detemir's binding to albumin is restoration of the normal hepatic to peripheral insulin gradient. Unlike endogenous insulin, conventional insulin preparations such as NPH partly bypass first pass hepatic clearance which explains their pronounced effect on peripheral targets such as adipose tissue and muscle. Insulin detemir however displays delayed transfer to peripheral tissues by virtue of its albumin binding property that exposes the liver to relatively higher levels of insulin. ${ }^{27}$ This mechanism not only limits hyperglycemia by decreasing hepatic glucose output, but also potentially reduces insulin-related weight gain. ${ }^{28}$

Its onset of action of 2 hours is comparable to both NPH and insulin glargine but in common with the latter, it lacks pronounced peak due to its favorable pharmacokinetic and pharmacodynamic properties. Isoglycemic studies have confirmed that duration of action is dose dependent, lasting up to 20 hours for doses of more than 0.4 units $/ \mathrm{kg}$ making a once daily dosing feasible. However for doses less than 0.4 units $/ \mathrm{kg}$, the duration of action is shorter hence twice daily dosing is recommended. ${ }^{25}$

\section{Efficacy and safety of insulin detemir}

Several studies conducted to assess the efficacy and safety of insulin detemir in type 1 diabetes have demonstrated that detemir offers comparable levels of $\mathrm{HbA}_{1 \mathrm{c}}$ reduction to both NPH and glargine as well as achieving better fasting plasma glucose (FPG) levels and less intrapatient variability compared to NPH. ${ }^{29-34}$ Moreover, these favorable outcomes of detemir were accompanied by a lower risk of hypoglycemia in overall and nocturnal hypoglycemia. ${ }^{29-34}$

The relative efficacy and safety of insulin detemir in type 2 diabetes has also been investigated in multinational, open-label, randomized trials. These studies compared insulin detemir to NPH and insulin glargine either as part of basal-bolus regimen or as an add-on to OADs. The major outcomes of these studies are summarized in Table 2.

\section{Glycemic control}

Raslova et al conducted a randomized study comparing once or twice daily insulin detemir added to prandial insulin aspart with once or twice daily NPH and prandial regular human insulin (RHI) in 395 type 2 diabetic patients. ${ }^{35}$ At the end of the study duration of 22 weeks, reductions in $\mathrm{HbA}_{1 \mathrm{c}}$ levels achieved with the detemir based regimen were comparable to that of NPH based regimen $(8.2 \%$ to $7.5 \%$ vs $8.1 \%$ to $7.5 \%$ respectively). Similarly, comparable FPG levels were achieved with the two insulin treatment regimes.

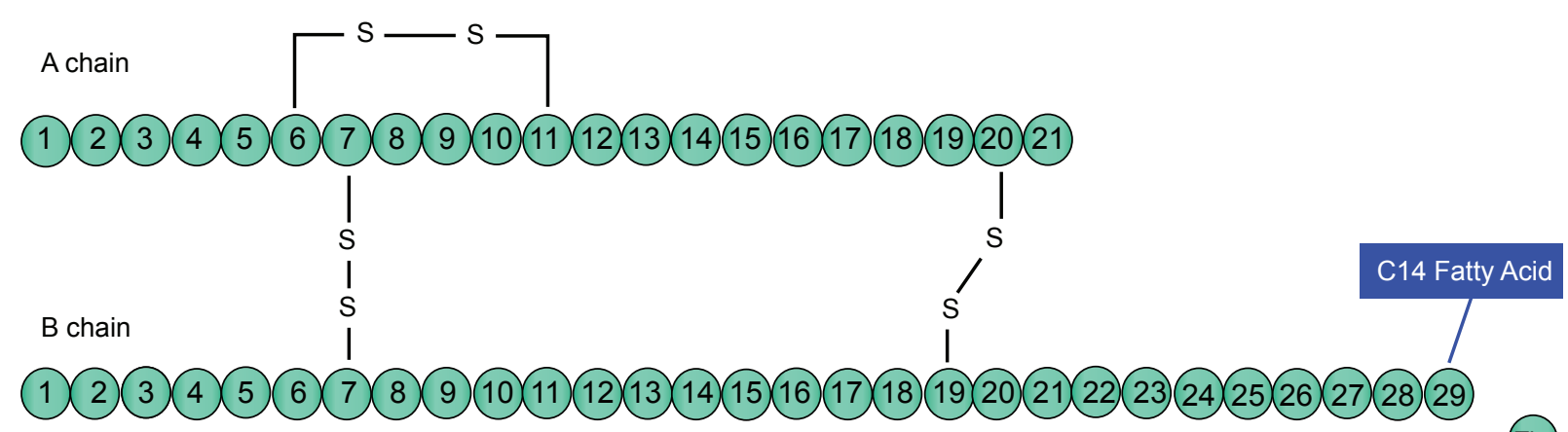

(Thr)

Figure I Insulin detemir. 
Table 2 Randomized trials comparing insulin detemir to NPH and glargine in basal-bolus regimen and as add-on to OADS

\begin{tabular}{|c|c|c|c|c|c|c|c|}
\hline \multirow[t]{2}{*}{ Study } & \multirow[t]{2}{*}{$\begin{array}{l}\text { Study duration } \\
\text { (weeks) }\end{array}$} & \multirow[t]{2}{*}{$\begin{array}{l}\text { Number } \\
\text { of patients }\end{array}$} & \multirow[t]{2}{*}{ Insulin therapy } & \multirow[t]{2}{*}{$\begin{array}{l}\text { Change in } \\
\operatorname{HbA}_{\mathrm{Ic}}(\%)\end{array}$} & \multirow[t]{2}{*}{$\begin{array}{l}\text { Incidence (\%) } \\
\text { of hypoglycemia }\end{array}$} & \multicolumn{2}{|c|}{$\begin{array}{l}\text { Change in weight } \\
(\mathrm{kg})\end{array}$} \\
\hline & & & & & & Major ${ }^{a}$ & Nocturnal \\
\hline \multirow[t]{3}{*}{ Philis-Tsimikas et $\mathrm{al}^{38}$} & 20 & 165 & detemir $^{d}$ & -1.6 & 0 & 2.4 & +1.2 \\
\hline & & 169 & detemire $^{\mathrm{e}}$ & -1.5 & 1.2 & 4.7 & +1.5 \\
\hline & & 164 & $\mathrm{NPH}$ & -1.7 & 0 & 13.4 & +1.6 \\
\hline \multirow[t]{2}{*}{ Hermansen et $\mathrm{al}^{37}$} & 26 & 227 & detemir + OADs & -1.8 & NA & $55 \%$ less & +1.2 \\
\hline & & 225 & $\mathrm{NPH}+\mathrm{OADs}$ & -1.9 & NA & NA & +2.8 \\
\hline \multirow[t]{2}{*}{ Rosenstock et a $\left.\right|^{39}$} & 52 & 291 & detemir + OAD & -1.4 & $0 / p t-y r$ & $1.3 / \mathrm{pt}-\mathrm{yr}$ & +3.0 \\
\hline & & 291 & Glargine & -1.5 & NA & $1.3 / \mathrm{pt}-\mathrm{yr}$ & +3.9 \\
\hline \multirow[t]{2}{*}{ Haak et a ${ }^{36}$} & 26 & 341 & detemir + aspart & -0.2 & $<2$ & 15.8 & +1.0 \\
\hline & & 164 & $\mathrm{NPH}+$ aspart & -0.4 & $<2$ & 23.6 & +1.8 \\
\hline \multirow[t]{2}{*}{ Raslova et al ${ }^{35}$} & 22 & 195 & detemir and aspart & -0.7 & 1.1 & 14.9 & $+0.5 \mathrm{I}$ \\
\hline & & 199 & $\mathrm{NPH}$ and $\mathrm{RHI}$ & -0.6 & 0.5 & 17.5 & +1.13 \\
\hline \multirow[t]{2}{*}{ Rosenstock et $\mathrm{al}^{39}$} & 52 & 582 & detemir and OAD & -1.4 & no significant & & +3.0 \\
\hline & & & glargine and OAD & -1.5 & difference & & +3.9 \\
\hline
\end{tabular}

aMajor hypoglycemia is where patients are not able to treat themselves.

Insulin detemir administered in the morning.

eInsulin detemir administered in the evening.

In a study of similar design undertaken by Haak et al 505 type 2 diabetic patients taking insulin aspart with once or twice daily detemir or NPH were followed up for 26 weeks duration. ${ }^{36}$ There was no significant difference in $\mathrm{HbA}_{1 \mathrm{c}}$ and fasting blood glucose (FBG) level reduction from baseline achieved with the detemir and NPH based regimes (7.9 to $7.6 \%$ vs $7.8 \%$ to $7.5 \%$ and -0.5 vs $-0.6 \mathrm{mmol} / \mathrm{L}$ respectively).

Two other randomized studies compared the efficacy of insulin detemir to that of NPH when used as basal therapy added to OADs. The first of these by Hermansen et al assessed the efficacy of twice daily insulin detemir added to OADs in comparison with twice daily NPH plus OADs in 475 type 2 diabetes patients inadequately controlled on OAD therapy alone ${ }^{37}$ Comparable reductions from baseline in both $\mathrm{HbA}_{\mathrm{lc}}$ and FBG were achieved with the two regimes (detemir: from $8.6 \%$ to $6.8 \%$ and 11.1 to $6.9 \mathrm{mmol} / \mathrm{L}$; NPH $8.5 \%$ to $6.6 \%$ and 10.8 to $6.6 \mathrm{mmol} / \mathrm{L}$ ). Philis-Tsimikas et al conducted a 20 weeks multicenter 3 -arm study enrolling a total of 504 insulin naive poorly controlled type 2 diabetes patients randomized to receive evening detemir, prebreakfast detemir or evening NPH added to OADs. ${ }^{38}$ There was no significant difference in $\mathrm{HbA}_{1 \mathrm{c}}$ reduction from baseline in the 3 arms of the study $(-1.58 \%,-1.48 \%$ and $-1.78 \%$ for the morning detemir, evening detemir and NPH respectively).

A 52-week randomized open-label noninferiority study by Rosenstock et al comparing a once daily regimen of insulin detemir and glargine added to OADs in 582 insulin naive type 2 diabetic patients. ${ }^{39}$ Patients were randomized to receive either of the two basal insulin on a $1: 1$ ratio and insulin dose was titrated aiming for a fasting glucose of $\leq 6 \mathrm{mmol} / \mathrm{L}$. Those patients randomized to receive detemir were allowed a second dose if premeal evening glucose levels were $>7 \mathrm{mmol} / \mathrm{L}, 55 \%$ of detemir patients completed the study on twice daily. Mean daily detemir dose was higher glargine. ${ }^{39}$ At the end of the study period, there was no significant difference in $\mathrm{HbA}_{1 \mathrm{c}}$ level and $\mathrm{FPG}$ achieved in the two arms $(8.6 \%$ to $7.2 \%$ and $7.1 \% ; 10.8 \mathrm{mmol} / \mathrm{L}$ to 7.1 and $7.2 \mathrm{mmol} / \mathrm{L}$ ). Another more recent trial once-daily dosing of insulin detemir provided 24-hour glycemic control, assessed by continuous glucose monitoring, similar to that of insulin glargine in patients with type 2 diabetes. ${ }^{40}$

\section{Risk of hypoglycemia}

The risk of hypoglycemia is one of the unwanted consequences of the treatment algorithm for early initiation and aggressive titration of insulin therapy in type 2 diabetes. This risk is particularly pronounced with conventional intermediate and long-acting insulin preparations such as NPH and ultralente due to peak activity and unpredictable profile. The smooth pharmacokinetic profile of the long-acting insulin analogues detemir and glargine delivers a relatively predictable and peak-less insulin level which is less prone to inflicting hypoglycemia.

In the two studies by Raslova et al and Haak et al which compared once or twice daily detemir with once or twice daily NPH in a basal-bolus regimen, there was no significant difference in the risk of both overall and nocturnal hypoglycemia between the two groups. ${ }^{35,36}$ However, the trial 
conducted by Hermansen et al comparing insulin detemir with NPH as add-on to OADs showed a 55\% less risk of nocturnal hypoglycemia in favor of detemir for comparable levels of improvements in glucose control. ${ }^{37}$ Similarly, in the study by Philis-Tsimikas et al evening detemir produced a $53 \%$ and $65 \%$ reduction in overall and nocturnal hypoglycemia respectively compared to evening NPH. ${ }^{38}$ The risk of nocturnal hypoglycemia was even much lower when detemir was administered in the morning (87\%). There was however no significant difference in risk of hypoglycemia between morning and evening detemir. The risk of hypoglycemia was also not significantly different when insulin detemir is compared with glargine as add-on to OADS. ${ }^{39}$

\section{Within-subject variability}

Variability in glucose profile is a measure of the degree of difference in the glucose-lowering effect of a given dose of insulin from one injection to another in the same patient at a specific point in time. ${ }^{41}$ It is often expressed in terms of the number of standard deviations from the median or mean glucose level obtained at a given time. A variable or unpredictable glucose level profile increases the risk of hypoglycemia and hence makes it difficult to safely titrate insulin dose to achieve optimal glucose control targets. ${ }^{42,43}$

Euglycemic clamp studies have shown that detemir is associated with less within-subject variability compared to NPH in both type 1 and type 2 diabetes. ${ }^{44,45}$ Clinical studies in patients with type 2 diabetes have also supported this observation. In the study by Raslova et al for instance, withinsubject variability in FBG with the use of insulin detemir with aspart was significantly less compared to NPH plus RHI (SD: 1.2 vs $1.5 \mathrm{mmol} / \mathrm{L}$ respectively, $\mathrm{p}<0.001) .{ }^{35}$ Similarly, the study by Haak et al also demonstrated less within-subject variability in FBG with the use of insulin detemir plus aspart than NPH plus aspart (SD: $1.3 \mathrm{vs} 1.4 \mathrm{mmol} / \mathrm{L}, \mathrm{p}=0.021) .{ }^{36}$ However, in the study by Hermansen et al comparing insulin detemir to NPH as add-on to OADs, there was no significant difference in within-subject variability between the two groups. ${ }^{37}$ Within-subject variability was also not significantly different between insulin detemir and glargine added to OADs in the study by Rosenstock et al. ${ }^{39}$

\section{Reduced insulin-related weight gain}

Insulin therapy in type 2 diabetes is commonly associated with weight gain, the magnitude of which depends on the total dose and type of insulin formulation used. As already discussed in previous sections, insulin detemir has favorable pharmacodynamic properties that are thought to provide a theoretical weight neutral advantage over the conventional basal insulin preparations.

The randomized trials comparing insulin detemir to NPH in type 2 diabetes both as basal-bolus regimen and as add-on to OADs revealed less weight gain for equivalent level of glucose control in favor of detemir $(\mathrm{p}<0.001$ to 0.05$) .{ }^{35-38}$ Insulin detemir has likewise caused less weight gain compared to glargine when added to oral agents at comparable level of glucose control $(\mathrm{p}=0.012)$. However, this difference was primarily related to completers on once daily detemir dose $(45 \%$ of insulin detemir group completed the study on once daily dose who received less total daily insulin dose compared with the other $55 \%$ completed the study on twice daily detemir dose). ${ }^{39}$

In a more recent multinational, 52-week, open-label, parallel-group, noninferiority, treat-to-target trial Hollander et al compared insulin detemir to glargine in patients with a diagnosis of type 2 diabetes for 12 months or more who had been receiving an OADs or insulin, with or without OADs, for more than 4 months were randomized in a 2:1 ratio to receive detemir or glargine. ${ }^{46}$ At 52 weeks, Mean weight gain was significantly lower with detemir than with glargine (2.8 vs $3.8 \mathrm{~kg}$; mean difference, -1.04 ; 95\% CI -2.08 to $-0.01 ; P<0.05)$. There was no significant difference between detemir and glargine in terms of change in fasting sugar (7.19\% and $7.03 \%$, respectively) or risk of hypoglycemia. The reduction in $\mathrm{HbA}_{1 \mathrm{c}}$ was not significantly affected by whether detemir was administered once or twice daily. At 52 weeks mean $\mathrm{HbA}_{1 \mathrm{c}}$ and mean decrease in $\mathrm{HbA}_{\mathrm{lc}}$ from baseline were more in insulin glargine group but non of these differences reached statistical significance. ${ }^{46}$ Although the magnitude of differences in weight gain between insulin detemir and the other basal insulins in the five studies outlined above appears too modest to be clinically relevant, the results have to be interpreted in the context of the short duration of follow-up of the studies (mean duration $\simeq 33 \mathrm{wks}$ ).

\section{The PREDICTIVE (Predictable Results and Experience in Diabetes through Intensification and Control to Target: an International Variability Evaluation)}

This is an ongoing large scale, multi-national, open label, prospective, observational study designed to assess the safety and efficacy of insulin detemir in day to day clinical practice. ${ }^{47}$ This study takes place in 20 countries and it is expected to enlist a population of over 30,000 patients. 
The subjects of this study include both type 1 and type 2 diabetes patients who are prescribed insulin detemir as part of routine clinical care. The primary endpoints for this study are serious adverse drug reactions, including major hypoglycemic episodes whereas the secondary endpoints include overall and nocturnal hypoglycemia, $\mathrm{HbA}_{1 \mathrm{c}}$, mean self-monitored fasting glucose, fasting glucose variability (calculated as the standard deviation of the last two to six fasting glucose measurements) and weight change.

So far, the outcomes of only a few subgroup analysis of the European PREDICTIVE cohorts have been released. The first of these is a 12-week subgroup analysis of the German cohort of 1832 type 2 diabetic patients who were transferred to insulin detemir with or without OADs from either an OAD only regimen $(n=1321)$, NPH insulin with or without OADs $(n=251)$ or insulin glargine with or without OADs $(n=260)$ by their physicians as part of routine clinical care. ${ }^{48}$ Three months after starting insulin detemir, no major hypoglycemic events occurred in any of the three groups. Overall nocturnal hypoglycemic events per patient were reduced by $84 \%, 80 \%$ and $90 \%$ for OADs only, $\mathrm{NPH} \pm \mathrm{OADs}$ and glargine \pm OADs groups respectively compared to baseline. In addition, both $\mathrm{HbA}_{1 \mathrm{c}}$ and fasting blood glucose levels were significantly reduced for all the subgroups $(P<0.0001)$. Fasting blood glucose variability was likewise significantly less marked with the use of insulin detemir compared to baseline for all the subgroups $(P=0.0008)$. The improvement in glycemic control observed with the use of insulin detemir in this analysis was also accompanied by a combined weight reduction of $0.9 \mathrm{kgs}$ across the subgroups $(P<0.0001)$.

In a preliminary report of a 3 month follow-up data from the Danish PREDICTIVE cohort of 312 type 1 and 77 type 2 diabetes patients, the incidence of major hypoglycemic episodes was reduced from 3.9/patientyears at baseline to 0.4 /patient-years at follow-up in type 1 patients $(P<0.0001)$, and from 1.0 to 0.0 /patient-years in type 2 patients $(P=0.125) .{ }^{49}$ The mean incidence of overall and nocturnal hypoglycemic episodes was also reduced in both type 1 ( -37.4 and $-17.7 /$ patient-years, $P<0.0001$ for both) and type 2 patients $(-17.7$ and -7.8 /patient-years, $P=0.0012$ and $P=0.0020$, respectively).

In a 12-week follow-up report on a Turkish PREDICTIVE cohort of 1285 type 1 and 777 type 2 diabetes patients switched from once or twice daily glargine ( \pm OADs) to once daily detemir in a basal-bolus regimen, significant reductions in both $\mathrm{HbA}_{1 \mathrm{c}}$ and FPG was obtained across the groups without any significant change in body weight. There was also significant reduction in overall and nocturnal hypoglycemic episode rates in favor of detemir $(P<0.0001) .{ }^{50}$

Another subgroup analysis of 2377 OAD treated type 2 diabetes patients of the European cohort of the PREDICTIVE study was reported after a mean follow-up of 14 weeks duration. ${ }^{51}$ These patients were prescribed insulin detemir as basal therapy with or without OADs. Compared to baseline, treatment with insulin detemir significantly reduced $\mathrm{HbA}_{1 \mathrm{c}}$, fasting glucose and within-patient fasting glucose variability $(-1.3 \%,-3.7 \mathrm{mmol} / \mathrm{L},-0.5 \mathrm{mmol} / \mathrm{L}$ respectively; $P<0.0001)$. There was also a small reduction in mean body weight $(-0.7 \mathrm{~kg} ; P<0.001)$. There was only one serious adverse drug reaction in the form of a major hypoglycemic episode in the detemir-treated group.

This ongoing observational study is widely anticipated to provide us ample evidence regarding the safety and efficacy of insulin detemir in routine clinical use and the relative benefits it offers in comparison with the other basal insulin preparations so as to guide clinicians to make rational choices. However, the study is open label and not randomized. Furthermore, lack of a control group is not ideal and improvement in diabetes care after enrolment in a clinical trial can be significant confounding factor and should be considered before making final conclusions from this project.

\section{Conclusion}

Insulin detemir is a novel soluble long-acting insulin analogue which is proven to be both safe and effective for use in type 2 diabetes. Its unique pharmacokinetic and pharmacodynamic properties provide a more predictable glucose profile and less risk of hypoglycemia compared to NPH when it is used in a basal-bolus regimen or as addon to OADs. It has also been proven to have a modest yet significant advantage over both NPH and glargine in terms of treatment related weight gain. Although the magnitude of the differences in weight gain between insulin detemir and the other basal insulins appears too modest to be clinically relevant, this has to be interpreted in the context of the relatively short duration of follow-up of the studies. More data needed on the long-term effect of insulin detemir on treatment related weight gain compared with other basal insulins and if this weight advantage achieved will become more significant clinically or be maintained long term at all. The long-term benefits of detemirs' weight advantage in term of cardiovascular risk would be difficult to assess. On the other hand, insulin detemir has a shorter half live compared with glargine and NPH with up to half of patients ending up 
on twice daily dose compared with once daily dose for the other two basal insulins.

Insulin detemir is therefore a rational choice for use as once daily or twice daily basal insulin in type 2 diabetes either in a basal-bolus regimen or ass add-on to OADs. The currently underway PREDICTIVE study is widely expected to contribute to the growing body of evidence on the efficacy and safety of insulin detemir in both type 1 and type 2 diabetes. It worth mentioning that the PREDICTIVE study is an open label trial with no control group and these factors should be taken in consideration before making any final conclusions from this project.

\section{Acknowledgment}

Support for the NIHR Manchester Biomedical Research Centre is acknowledged.

\section{Disclosures}

Yared N Demssie has no conflict of interest to declare. Handrean Soran and Naveed Younis have received grant support, lecture and consultation fees from several pharmaceutical manufacturers including Novo Nordisk.

The authors were invited by the Editorial board of Vascular Health and Risk Management to write this review. No fee has been received for preparation of the manuscript.

\section{References}

1. The Diabetes Control and Complications Trial Research Group. The effect of intensive treatment of diabetes on the development and progression of long term complications in insulin-dependent diabetes mellitus. N Eng J Med. 1993;329:977-986.

2. UK Prospective Diabetes Study (UKPDS) Group. Intensive blood glucose control with sulphonylureas or insulin compared with conventional treatment and risk of complications in patients with type 2 diabetes (UKPDS 33). Lancet. 1998;352:837-853.

3. Holman RR, Paul SK, Bethel MA, Matthews DR, Neil HA. 10-year follow up of intensive glucose control in type 2 diabetes. N Engl J Med. 2008;359:1577-1589.

4. American Diabetes Association. Standards of medical care in diabetes. Diabetes Care. 2008;31 Supp1 1:S12-S54.

5. International Diabetes Federation (IDF) Task Force on Clinical Practice Guidelines. Global guideline for type 2 diabetes. Available at http://www.idf.org/home/index.cfm?node=1449. Accessed March 09, 2009.

6. Fox KM, Gerber RA, Bolinder B, Chen J, Kumar S. Prevalence of inadequate glycaemic control among patients with type 2 diabetes in the United Kingdom general practise research database: a series of retrospective analyses of data from 1998 through 2002. Clin Ther. 2006;28:388-395.

7. Bo S, Cavallo-Perin P, Gentile L, et al. Relationship of residual beta-cell function, metabolic control and chronic complications in type 2 diabetes mellitus. Acta Diabetol. 2000;37:125-129.

8. Nathan DM, Buse JB, Davidson MB, et al. Management of hyperglycaemia in type 2 diabetes: a consensus algorithm for the initiation and adjustment of therapy: a consensus statement from the American Diabetes Association and the European Association for the Study of Diabetes. Diabetes Care. 2006;29:1963-1972.
9. Norris SL, Zhang X, Avenell A, et al. Long term effectiveness of lifestyle and behavioural weight loss interventions in adults with type 2 diabetes: a meta-analysis. Am J Med. 2004;117:762-774.

10. Haffner SM, D’Agostino R Jr, Mykkanen L, et al. Insulin sensitivity in subjects with type 2 diabetes. Relationship to cardiovascular risk factors. the Insulin Resistance Atherosclerosis Study. Diabetes Care. 1999;22:562-568.

11. Gottesman I. Managing obesity and glycemic control in insulin-using patients: clinical relevance and practise recommendations. Diabetes Res Clin Pract. 2004;65 Suppl:S17-S22.

12. Sinha A, Formica C, Tsalamandris C, et al. Effects of insulin in body composition in patients with insulin-dependent and non-insulin dependent diabetes. Diabet Med. 1996;13:40-46.

13. Yki-Jarvinen H, Ryysy L, Kauppila M, et al. Effect of obesity on the response to insulin therapy in non-insulin dependent diabetes mellitus. J Clin Endocrinol Metab. 1997;82:4037-4043.

14. Peters AL. The clinical implications of insulin resistance. Am J Manag Care. 2000;6(13 Suppl):S668-S674.

15. Heller S. Weight gain during insulin therapy in patients with type 2 diabetes mellitus. Diabetes Res Clin Pract. 2004;65 Suppl: S23-S27.

16. Snoek FJ, Barriers to good glycaemic control: the patient's perspective. Int J Obes Relat Metab Disord. 2000;24 Suppl 3:S12-S20.

17. Purnell JQ, Weyer C. Weight effect of current and experimental drugs for diabetes mellitus: from promotion to alleviation of obesity. Treat Endocrinol. 2003;2:33-47.

18. Pinget $M$, Jeandidier N. Long-term safety and efficacy of intraperitoneal insulin infusion by means of implantable pumps. Horm Metab Res. 1998;30:475-486.

19. Makimattila S, Nikkila K, Yki-Jarvinen H. Causes of weight gain during insulin therapy with and without metformin in patients with type 2 diabetes mellitus. Diabetologia. 1999;42:406-412.

20. Goudswaard AN, Furlong NJ, Rutten GE, et al. Insulin monotherapy versus combinations of insulin with oral hypoglycaemic agents in patients with type 2 diabetes mellitus. Cochrane Database Sys Rev. 4:CD003418.

21. Gaede P, Vedel P, Larsen N, et al. Multifactorial intervention and cardiovascular disease in patients with type 2 diabetes. $N$ Eng $J$ Med. 2003;348:383-393.

22. Whittingham JL, Havelund S, Jonassen L. Crystal structure of a prolonged-acting insulin with albumin binding properties. Biochemistry. 1997;36:2826-2831.

23. Kurtzhas P, Havelund S, Jonassen I, et al. Albumin binding and timeaction of acylated insulin in various species. J Pharm Sci. 1996;85: 304-308.

24. Soran H, Younis N. Insulin detemir: a new basal insulin analogue. Diabetes Obes Metab. 2006;8:26-30.

25. Pieber TR, Plank J, Georzer E, et al. Duration of action, pharmacodynamci profile and between-subject variability of insulin detemir in subjects with type 1 diabetes. Diabetes. 2002;51 Suppl 2:A214.

26. The role of new basal insulin analogues in the initiation and optimisation of insulin therapy in type 2 diabetes. Acta Diabetol. 2008;45: 253-268.

27. Hermansen K, Davies M. Does insulin detemir have a role in reducing risk of insulin-associated weight gain. Diabetes Obes Metab. 2007;9:209-217.

28. Bush MA. Intensive diabetes therapy and body weight: focus on insulin detemir. Endocrinol Metab Clin North Am. 2007;36 Suppl 1:33-44.

29. Home P, Bartley P, Russel-Jones D, et al. Insulin detemir offers improved glycaemic control compared to NPH insulin in people with type 1 diabetes: a randomised clinical trial. Diabetes Care. 2004;27:1081-1087.

30. Piber TR, Treichel H-C, Robertson LI, et al. Insulin detemir plus insulin aspart is associated with less risk of major as well as nocturnal hypoglycaemia than insulin glargine plus insulin aspart at comparable levels of glycaemic control in type 1 diabetes. Diabetologia. 2005; 48:A92. 
31. Russel-Jones D, Simpson R, Hyelleberg B, et al. Effects of QD insulin detemir or neutral protamine Hagedron on blood glucose control in patients with type 1 diabetes mellitus using a basal-bolus regimen. Clin Ther. 2004;26:724-736.

32. Hermansen K, Fontaine P, Kukolja KK, et al. Insulin analogues (insulin detemir and insulin aspart) versus traditional human insulins (NPH insulin and regular human insulin) in basal-bolus therapy for patients with type 1 diabetes. Diabetologia. 2004;47:622-629.

33. Kolendorf K, Ross GP, Pavlic-Renar I, et al. Insulin detemir lowers the risk of hypoglycaemia and provides more consistent plasma glucose levels compared with NPH insulin in type 1 diabetes. Diabet Med. 2006;23:729-735.

34. Robertson KJ, Schonle E, Gucev Z, et al. Insulin detemir compared with NPH insulin in children and adolescents with type 1 diabetes. Diabet Med. 2007;24:27-34

35. Raslova K, Bogoev M, Raz I, et al. Insulin detemir and insulin aspart: a promising basal-bolus regimen for type 2 diabetes. Diabetes Res Clin Pract. 2004;66:193-201.

36. Haak T, Tiengo A, Draeger E, Suntum M, Waldhaus W. Lower withinsubject variability of fasting blood glucose and reduced weight gain with insulin detemir compared to NPH insulin in patients with type 2 diabetes. Diabetes Obes Metab. 2005;7:56-64.

37. Hermansen K, Davies M, Derezinski T, et al. A 26 week, randomized, parallel, treat to target trail comparing insulin detemir with NPH insulin ass add-on therapy to oral glucose-lowering drugs in insulin-naïve people with type 2 diabetes. Diabetes Care. 2006;29:1269-1274.

38. Philis-Tsimikas A, Charpentier G, Clauson P. Comparison of once-daily insulin detemir with NPH insulin added to a regimen of oral antidiabetic drugs in poorly controlled type 2 diabetes. Clin Ther. 2006;28: $1569-1581$

39. Rosenstock J, Davies M, Home PD, et al. A randomized treat to target trial comparing insulin detemir with insulin glargine when administered as add-on to glucose lowering drugs in insulin-naïve people with type 2 diabetes. Diabetologia. 2008;51:408-416.

40. King AB. Once-daily insulin detemir is comparable to once-daily insulin glargine in providing glycaemic control over $24 \mathrm{~h}$ in patients with type 2 diabetes: a double-blind, randomized, crossover study. Diabetes Obes Metab. 2009;11:69-71.

41. Heise T and Pieber TR. Towards peakless, reproducible and long-acting insulins. An assessment of the basal analogues based on isoglycaemic clamp studies. Diabetes Obes Metab. 2007;9:648-659.
42. Heinemann L. Variability of insulin absorption and insulin action. Diabetes Technol Ther. 2002;4:673-682.

43. Russell-Jones D. Insulin detemir: improving the predictability of glycaemic control. Int J Obes Relat Metab Disord. 2004;28: S29-S34.

44. Heise T, Nosek L, Ronn BB, et al. Lower within-subject variability of insulin detemir in comparison to NPH insulin and insulin glargine in people with type 1 diabetes. Diabetes. 2004;53:1614-1620.

45. Klein O, Lynge J, Endahl L, et al. Albumin bound basal insulin analogues (insulin detemir and NN344): comparable time-action profiles but less variability than insulin glargine in type 2 diabetes. Diabetes Obes Metab. 2007;9:290-299.

46. Hollander P, Cooper J, Bregnhøj J, et al. A 52-week, multinational, open-label, parallel-group, noninferiority, treat-to-target trial comparing insulin detemir with insulin glargine in a basal-bolus regimen with mealtime insulin aspart in patients with type 2 diabetes. Clin Ther. 2008;30:1976-1987.

47. Lüddeke HJ, Sreenan S, Aczel S, et al; PREDICTIVE Study Group. PREDICTIVE-a global, prospective observational study to evaluate insulin detemir treatment in types 1 and 2 diabetes: baseline characteristics and predictors of hypoglycaemia from the European cohort. Diabetes Obes Metab. 2007;9:428-434.

48. Meneghini LF, Rosenberg KH, Koenen C, et al. Insulin detemir improves glycaemic control with less hypoglycaemia and no weight gain in patients with type 2 diabetes who were insulin naive or treated with NPH or insulin glargine: clinical practice experience from a German subgroup of the PREDICTIVE study. Diabetes Obes Metab. 2007;9:418-427.

49. Hermansen K, Lund P, Clemmensen K, et al; on behalf of the Danish PREDICTIVE study. 3-Month Results from Denmark within the Globally Prospective and Observational Study to Evaluate Insulin Detemir Treatment in Type 1 and Type 2 Diabetes: The PREDICTIVE Study group. Rev Diabet Stud. 2007;4:89-97.

50. Yenigun M, Honka M. Switching patients from insulin glargine-based basal-bolus regimens to a once daily insulin detemir-based basal-bolus regimen: results from a subgroup of the PREDICTIVE study. Int J Clin Pract. 2009;63:425-432.

51. Dornhorst A, Lüddeke HJ, Sreenan S, et al; PREDICTIVE Study. Insulin detemir improves glycaemic control without weight gain in insulin-naïve patients with type 2 diabetes: subgroup analysis from the PREDICTIVE study. Int J Clin Pract. 2008;62:659-665.
Vascular Health and Risk Management

\section{Publish your work in this journal}

Vascular Health and Risk Management is an international, peerreviewed journal of therapeutics and risk management, focusing on concise rapid reporting of clinical studies on the processes involved in the maintenance of vascular health; the monitoring, prevention and treatment of vascular disease and its sequelae; and the involvement of

\section{Dovepress}

metabolic disorders, particularly diabetes. This journal is indexed on PubMed Central and MedLine. The manuscript management system is completely online and includes a very quick and fair peer-review system, which is all easy to use. Visit http://www.dovepress.com/ testimonials.php to read real quotes from published authors. 